\title{
Contact with a nurse practitioner: a short-term evaluation study in Parkinson's disease and dystonia
}

\author{
M. Jahanshahi ${ }^{1,2}$, R.G. Brown ${ }^{2}$, C. Whitehouse ${ }^{1}$, N. Quinn ${ }^{1}$ and C.D. Marsden ${ }^{1,2}$ \\ 'Department of Clinical Neurology, Institute of Neurology, Queen Square, London, and ${ }^{2}$ Medical \\ Research Council, Human Movement and Balance Unit, Queen Square, London, UK \\ Correspondence to: M. Jahanshahi, MRC Human Movement and Balance Unit, The National \\ Hospital for Neurology and Neurosurgery, Queen Square, London WC1N 3BG, UK
}

\begin{abstract}
Forty patients with Parkinson's disease and 24 patients with dystonia took part in a study aiming to assess the value of access to and contact with a nurse practitioner over a 6 month period. Patients in each group were randomly allocated to "intervention" or "control" groups, which were matched on important variables. All patients completed a set of questionnaires relating to psychosocial function at two time points separated by 6 months. In the intervening period, those allocated to the "intervention" group received two home visits and five telephone calls from the nurse practitioner. This contact was not provided to the "control" group. The nurse practitioner had a major impact on the provision of information and the facilitation of referral to other health-care agencies. The results of an independent assessment indicated that the patients in the "intervention" programme had found access to and contact with a nurse practitioner of great value. In contrast, the results of the questionnaire assessment did not reveal any statistically significant change in psychosocial functioning from the first to the second assessment for either the "intervention" or "control" groups. The lack of change in the questionnaire measures is discussed in terms of possible sampling bias and the duration of intervention and follow-up. Recommendations are made for future studies, and for the possible provision of clinical services.
\end{abstract}

Keywords: Dystonia - Management - Nurse practitioner - Outcome study - Parkinson's disease

\section{INTRODUCTION}

The onset of any severe illness is a life crisis that can have a major effect on the psychological well-being and social functioning of sufferers and their carers. When that disease is chronic, progressive and disabling, such as Parkinson's disease (PD) or dystonia, its impact will be even greater. Throughout the course of the illness, the patient and their carers are confronted by new challenges and demands, as the level of impairment increases, and their life circumstances change. The process of adaptation, therefore, must be continuous (Holmes and Rahe, 1967; Moos, 1977; Cohen and Lazarus, 1979; Turk, 1979). Unfortunately, a significant proportion of patients with PD or dystonia have problems adjusting to their illness. In PD, there is a tendency to withdraw prematurely from purposeful social and individual activity (Oxtoby, 1982; Gotham et al., 1986; MacCarthy and Brown, 1989). Depression is also common, with between $25 \%$ and $30 \%$ of patients with PD or dystonia reporting moderate to severe levels, which may persist over relatively long periods of time (Jahanshahi and
Marsden, 1988, 1990a,b; Brown et al., 1988). Research in a range of chronic medical disorders has highlighted the importance of psychosocial factors to eventual adjustment and outcome of the disorder (Moos and Solomon, 1964; Burton et al., 1986; Shaw et al., 1986; Felton and Revenson, 1984).

Unfortunately, little of this research has had any impact on the clinical management of patients with chronic neurological disease. Where factors such as depression are even considered, they are usually seen as further manifestations of the underlying disease or an understandable reaction to the physical symptoms. In either event, management is aimed at palliative treatment of the symptoms either through medication, or injection with botulinum toxin in the case of dystonia. The World Health Organization (WHO, 1992) consider that this traditional medical model of disease is inappropriate to meet the demands of managing chronic illness. They urge that the emphasis is shifted from treatment of the signs and symptoms, to the broader consequences of disease, and the manage- 
ment of disability and handicap. The same message comes through in the recent report by the Royal College of Physicians (1990). They noted that in standard neurological practice the psychosocial needs of patients with chronic neurological illnesses were rarely addressed. In general, it was concluded, there is a failure to: (1) impart early information about the diagnosis and about its meaning to the patient; (2) inform the patient about relevant associations; (3) provide physical aids, structural alterations to the home, or supporting services such as community physiotherapy; (4) ensure adequate local facilities for welfare counselling, home nursing and physiotherapy, day care and holiday relief. To overcome some of these shortcomings, the report recommended that "some districts should appoint and evaluate the effectiveness of 'keyworkers' assigned to individual patients." Such keyworkers, it was suggested, might have training in nursing, social work or physiotherapy. One model adopted is that of the nurse practitioner, a specialist nurse able to provide information, practical help, advice and support. Contact with a nurse practitioner has proven successful in primary care (Drury et al., 1988) and the management of other chronic illnesses such as rheumatoid arthritis (Hill, 1986, 1992).

To date there has been no systematic investigation of a programme of management aimed at the physical and psychosocial needs of patients with chronic neurological disease. This study assesses the value of providing access to, and contact with, a nurse practitioner over a 6 month period in a sample of patients with either PD or dystonia.

\section{METHODS}

\section{Sample}

Forty patients with PD (25 male, 15 female) and 24 patients with dystonia (13 male, 11 female) were recruited from the National Hospital for Neurology and Neurosurgery, London. The selection criteria for the PD patients were: a diagnosis of idiopathic disease; current treatment with dopaminergic medication; Hoehn and Yahr (Hoehn and Yahr, 1967) stage of illness of II or above; age less than 70 years; no clinical evidence of dementia. The dystonia patients had primary or secondary generalized or segmental dystonia, and were aged 16 or above. All patients lived within a 50 mile radius of the hospital. The mean age of the PD patients was 63.7 years (S.D. 6.3) with an average age of onset of 53.6 years (S.D. 10.6), and a duration of illness of 10.1 years (S.D. 6.5 , range $1-25$ years). The dystonia patients had a mean age of 52.9 years (S.D. 16.1), a mean age of onset of 33.6 years (S.D. 19.6) and a mean duration of 19.3 years (S.D. 11.5, range 5-44).

\section{Assessment measures}

After providing informed consent, half of the patients in each sample were randomly allocated to an "intervention" and the other half to a "control" group. All patients completed a set of questionnaires relating to psychological and social functioning on two occasions, separated by an interval of 6 months. For those allocated to the "intervention" group, the first set of questionnaires were completed before the first contact with the nurse practitioner, and the second, immediately after the end of this contact which had lasted over a 6 month period. The questionnaire booklet consisted of the Beck Depression Inventory (BDI; Beck et al., 1961), Spielberger Trait Anxiety Scale (Spielberger et al., 1970), Acceptance of Illness Scale (Felton et al., 1984), the positive affect items from Bradburn's Present Feelings Scale (Bradburn, 1969), Rosenberg's Self-esteem Scale (Rosenberg, 1965), measuring both positive self-esteem and self-deprecation, Functional Disability Questionnaire (Jahanshahi and Marsden, 1990a), a rating of perceived disfigurement (Jahanshahi and Marsden, 1990a) and the Body Concept Scale (Jahanshahi and Marsden, 1990a). In addition to these outcome measures, a number of factors were assessed which may play a role as intervening or mediating variables between illness-related stress and adaptation. These variables include the quality and quantity of social support (Social Support Questionnairs; Sarason et al., 1983), the range of coping strategies available to the individual (Ways of Coping Checklist; Folkman and Lazarus, 1980; Jahanshahi, 1991) and personality (Eysenck Personality Questionnaire; Eysenck and Eysenck, 1975).

Finally, a problem checklist was devised to identify potential problems for intervention by the nurse practitioner. This covered living conditions, employment, finances, mobility, leisure activities and holidays, nature of medical contact and use of aids and equipment.

\section{Intervention programme}

The intervention programme consisted of two home visits and five telephone contacts from the nurse practitioner, spread over a period of 6 months. The contact period of 6 months started and ended with a home visit from the nurse practitioner. Each home visit lasted three or more hours, depending on the needs of particular patients. In the intervening period, the nurse practitioner made five telephone contacts 
with each patient. The programme defined three main roles for the nurse practitioner during the home visits and telephone contacts: (1) provision of information about the illness and self-help techniques, through written material and discussion; (2) assessment of needs and facilitation of contact with other helping professions (e.g. physiotherapist, occupational therapist, speech therapist, social worker); (3) provision of support. In this latter role, no direct or systematic counselling was provided but contact with a nurse practitioner was considered to include an indirect or non-specific supportive aspect. In addition to the scheduled contacts, the patients in the intervention group were free to telephone the nurse practitioner at any time during the trial.

\section{Independent assessment of patient satisfaction}

At the end of the trial, the patients allocated to the intervention group were contacted by investigators not involved in the intervention programme. They were sent a letter explaining the independent and anonymous nature of the assessment. They were asked seven questions.

(1) "How useful was contact with the nurse practitioner for you?" The usefulness of the contact was rated on a 0 (not at all useful) to 10 (very useful) scale.

(2) "Which aspect(s) of the contact with the nurse practitioner did you find most useful?" Patients were asked to rank five possible aspects of the contact in order of usefulness. These were: (i) information given about the illness and its treatment; (ii) opportunity to talk to someone about the illness and the problems caused by it; (iii) referral to other health professionals; (iv) sorting out practical problems; (v) knowing that someone (nurse practitioner) could be contacted if problems arose.

(3) "Please indicate whether you found the personal contact during the home visits or the telephone contacts most useful."

(4) "Which aspects of contact with the nurse practitioner could be improved?" Subjects were asked to indicate whether they felt that the intervention was: (i) too short; (ii) required more home visits and telephone contacts; (iii) should concentrate on personal and emotional problems, and not just practical issues.

(5) "How useful do you think contact with a nurse practitioner would be for others with PD or dystonia?" The usefulness of the contact to others was rated on a 0 (not at all useful) to 10 (very useful) scale.
(6) "Do you think that making contact with a nurse practitioner more widely available should be an important priority of the Health Service?" Subjects indicated yes or no.

(7) "In your own words, can you please describe your own experience of contact with a nurse practitioner." Subjects were given space to provide their own comments. The responses of each of the 26 patients were transcribed verbatim and were classified as "positive", "neutral" or "negative" by three independent raters. In the event of disagreement a majority rating was given.

\section{RESULTS}

\section{Psychosocial variables-initial assessment}

The sex ratio of the patients in the intervention and control groups did not differ $(p>0.10)$ Table I). The patients allocated to the two groups did not differ in terms of age, age of onset, or duration of illness. No significant difference $(p>0.01)$ was found between the intervention and control groups, for either PD or dystonia patients, for the putative intervening variables, social support, coping and personality (Table I).

\section{Change in psychosocial measures over 6 months}

The mean scores of the patients in the "intervention" and "control" groups at the time of the first and second assessments on the outcome measures are presented in Table II.

Comparing pre- and post-intervention results, for the PD patients allocated to the "intervention" group, scores on the majority (seven out of nine) of the psychosocial measures, albeit very slightly, had changed in the direction indicating improvement. However, these changes failed to reach significance $(p>0.05)$. The greatest change was in terms of reduction of depression and anxiety. In contrast, the PD patients allocated to the "control" group showed change indicative of improvement only on three of the nine measures, although again none of the changes was significant.

The patients with dystonia portrayed a different picture. Those randomly allocated to the "intervention" group showed non-significant change indicative of deterioration on almost all measures. In contrast, those allocated to the "control" group showed non-significant change indicative of improvement on seven out of nine measures. Therefore, the direction of change obtained in the "intervention" and "control" groups for the dystonia patients was opposite to that predicted. 
TABLE I. Demographic variables and the mean scores (and S.D.) on the putative intervening or mediating variables of the patients with Parkinson's disease or dystonia allocated to the "intervention" or "control" groups

\begin{tabular}{|c|c|c|c|c|}
\hline & \multicolumn{2}{|c|}{ Parkinson's disease } & \multicolumn{2}{|c|}{ Dystonia } \\
\hline & $\begin{array}{l}\text { Intervention } \\
\text { group }\end{array}$ & $\begin{array}{l}\text { Control } \\
\text { group }\end{array}$ & $\begin{array}{l}\text { Intervention } \\
\text { group }\end{array}$ & $\begin{array}{l}\text { Control } \\
\text { group }\end{array}$ \\
\hline Sex ratio $(M: F)$ & $10: 10$ & $15: 5$ & $7: 5$ & $6: 6$ \\
\hline Age & $63.1(4.0)$ & $64.3(8.0)$ & $51.6(12.7)$ & $53.6(19.5)$ \\
\hline Age at onset (years) & $52.0(8.3)$ & $55.6(12.3)$ & $29.5(20.2)$ & $37.4(19.1)$ \\
\hline Duration of illness (years) & $11.2(6.9)$ & $8.8(6.1)$ & $22.0(12.4)$ & $16.2(10.3)$ \\
\hline \multicolumn{5}{|l|}{ Social support } \\
\hline Quantity & $2.8(1.8)$ & $2.5(1.3)$ & $3.2(1.8)$ & $2.5(1.2)$ \\
\hline Quality (1 = low, $6=$ high) & $5.4(0.5)$ & $5.3(0.5)$ & $5.1(1.0)$ & $5.1(0.7)$ \\
\hline \multicolumn{5}{|l|}{ Ways of coping checklist } \\
\hline$(1-5 ; 1=$ never, $5=$ always $)$ & $2.8(0.2)$ & $2.8(0.4)$ & $2.9(0.2)$ & $2.8(0.4)$ \\
\hline \multicolumn{5}{|l|}{ Eysenck Personality Questionnaire } \\
\hline Extraversion $(0-21)$ & $9.5(6.0)$ & $7.2(4.8)$ & $12.2(5.1)$ & $9.8(1.9)$ \\
\hline Neuroticism (0-23) & $12.9(5.0)$ & $11.6(5.8)$ & $11.0(7.1)$ & $14.2(4.2)$ \\
\hline
\end{tabular}

TABLE II. Mean scores (and S.D.) of the PD and dystonia patients allocated to the "intervention" and "control" groups at the first and second assessments

\begin{tabular}{|c|c|c|c|c|}
\hline \multirow[b]{2}{*}{ Measure (possible range of scores) } & \multicolumn{2}{|c|}{ Intervention group } & \multicolumn{2}{|c|}{ Control group } \\
\hline & Assessment 1 & Assessment 2 & Assessment 1 & Assessment 2 \\
\hline $\begin{array}{l}\text { PD patients } \\
\text { Beck Depression Inventory (0-63) } \\
\text { Spielberger Trait Anxiety Scale } \\
\text { (20-80) } \\
\text { Acceptance of IIIness Scale (1-5) } \\
\text { Bradburn Positive Feelings }{ }^{1}(5-20) \\
\text { Rosenberg Self-esteem }{ }^{1}(5-20) \\
\text { Rosenberg Self-deprecation }(5-20) \\
\text { Functional Disability }(27-108) \\
\text { Disfigurement }(0-10) \\
\text { Body Concept }(22-154)\end{array}$ & $\begin{array}{r}14.0(5.7) \\
44.2(8.4) \\
\\
3.2(1.4) \\
11.5(2.8) \\
13.9(2.7) \\
11.9(2.8) \\
53.1(19.7) \\
3.5(2.4) \\
92.0(19.4)\end{array}$ & $\begin{array}{l}12.6(6.6) \\
43.2(10.4) \\
\\
2.9(0.9) \\
11.7(3.6) \\
14.3(2.6) \\
11.6(3.3) \\
54.2(19.4) \\
3.3(2.0) \\
92.5(22.5)\end{array}$ & $\begin{array}{l}13.9(6.7) \\
43.6(11.8) \\
\\
3.2(1.2) \\
11.2(3.8) \\
14.2(1.8) \\
11.6(3.4) \\
49.7(14.2) \\
2.5(2.5) \\
91.9(17.4)\end{array}$ & $\begin{array}{l}13.1(6.3) \\
43.9(10.9) \\
\\
3.4(1.3) \\
11.4(3.1) \\
13.5(1.6) \\
12.5(2.7) \\
54.2(19.4) \\
2.4(2.7) \\
97.7(16.2)\end{array}$ \\
\hline $\begin{array}{l}\text { Dystonia patients } \\
\text { Beck Depression Inventory (0-63) } \\
\text { Spielberger Trait Anxiety Scale } \\
(20-80) \\
\text { Acceptance of Illness Scale (1-5) } \\
\text { Bradburn Positive Feelings }{ }^{1}(5-20) \\
\text { Rosenberg Self-esteem }^{1}(5-20) \\
\text { Rosenberg Self-deprecation }(5-20) \\
\text { Functional Disability }(27-108) \\
\text { Disfigurement }(0-10) \\
\text { Body Concept }(22-154)\end{array}$ & $\begin{array}{c}9.9(8.9) \\
40.6(14.4) \\
\\
3.0(1.0) \\
12.3(3.9) \\
14.6(2.5) \\
11.6(2.5) \\
55.7(21.2) \\
4.3(2.5) \\
91.7(24.7)\end{array}$ & $\begin{array}{c}10.6(6.5) \\
41.5(13.9) \\
\\
3.4(1.8) \\
12.3(2.6) \\
13.8(2.5) \\
11.8(2.5) \\
56.6(19.2) \\
4.1(1.9) \\
101.5(23.7)\end{array}$ & $\begin{array}{c}15.7(10.1) \\
49.5(12.5) \\
\\
3.5(0.69) \\
11.0(2.6) \\
12.8(2.8) \\
12.3(3.3) \\
58.8(10.3) \\
5.3(2.5) \\
97.0(15.3)\end{array}$ & $\begin{array}{c}15.6(13.9) \\
46.5(12.9) \\
\\
3.3(1.0) \\
10.6(2.3) \\
13.5(3.7) \\
11.3(4.5) \\
56.4(18.5) \\
5.1(2.0) \\
104.0(24.4)\end{array}$ \\
\hline
\end{tabular}

${ }^{1}$ Higher scores indicate positive or beneficial responses, for remaining scales higher scores indicate poorer adjustment.

Practical impact of the nurse practitioner Practical advice and referral to other health professionals. Table III shows the nature and frequency of interventions made by the nurse practitioner on the basis of her home visit, and subsequent contact with the patients over the following 6 months. An intervention of some type was made in all but one case. The majority of patients received direct practical advice or information from the nurse practitioner herself. The most common form of information given was financial, regarding income support and mobility allowance. Other common needs concerned the way to obtain a disability sticker for their car, dietary advice, and information regarding holidays for the

192 Behavioural Neurology . Vol 7 . 1994 
TABLE III. Practical outcome of nurse practitioner intervention

\begin{tabular}{lcc}
\hline & Number of cases & $\%$ \\
\hline Practical advice/information & 30 & $90.6 \%$ \\
provision by nurse practitioner & & \\
Referral to: & & \\
Physiotherapist & 2 & $6.2 \%$ \\
Occupational therapist & 6 & $18.9 \%$ \\
Dietician & 2 & $6.2 \%$ \\
Speech therapist & 3 & $9.3 \%$ \\
Continence advisor & 2 & $6.2 \%$ \\
Dentist & 0 & $0 \%$ \\
Optician & 0 & $0 \%$ \\
Chiropodist & 1 & $3.1 \%$ \\
Psychologist/psychiatrist & 1 & $3.1 \%$ \\
Neurologist & 5 & $15.6 \%$ \\
Driver assessment centre & 1 & $3.1 \%$ \\
\hline
\end{tabular}

disabled. The other interventions made by the nurse practitioner concerned referrals to other health professionals through the patient's own general practitioner. In total, 22 referrals were arranged in the 6 month period.

Telephone contacts. In addition to the scheduled regular telephone contacts, all of the patients in the intervention group were invited to telephone the nurse practitioner whenever they needed to. In the event, 18 patients made use of this service, making a total of 63 calls. The frequency ranged from 1 to 15 (mean 3.5 calls). The majority of these calls $(63 \%)$ were classifiable as for a "chat" or for "support". Of the remainder, $32 \%$ were regarding specific information about medication, health-related problems and appointments, and $5 \%$ concerned requests for specific help such as extra referrals to occupational or physiotherapists.

\section{Results of the "independent assessment"}

Completed questionnaires for the "independent assessment" were received from 26 of the $32(81.3 \%)$ PD and dystonia patients allocated to the intervention group. With regard to the seven specific items described in the methods:

(1) The mean rating was 8.5 (S.D. 2.0). Half rated the contact as 10 , i.e. "very useful".

(2) The aspects of the contact rank ordered in terms of usefulness were: "Opportunity to talk to someone about the illness and the problems caused by it", "Knowing that someone [nurse practitioner] could be contacted if problems arose", "Referral(s) to other health professionals", "Sorting out practical problems", "Information given about the illness and its treatment".
(3) The majority of the sample $(88.5 \%)$ considered the home visits to be the most useful aspect of the contact with the nurse practitioner.

(4) The majority of subjects $(80.8 \%)$ thought that the duration of the contact needed to be prolonged. A total of $38.5 \%$ considered it necessary for the contact with the nurse practitioner to be made more intensive. A need to change the "nature" of the contact with the nurse practitioner was considered necessary by less than a quarter $(24 \%)$ of the sample.

(5) More than half $(58 \%)$ of the patients were of the opinion that contact with a nurse practitioner would be found "very useful" by other sufferers (mean rating 9.0, S.D. 1.4).

(6) Patients almost unanimously (25 out of 26, $96.2 \%$ ) agreed that contact with a nurse practitioner should be an important priority of the Health Service.

(7) Twenty-four of the 26 replies were rated unanimously as "positive" and two were rated as "neutral". None was rated as "negative". Examples of the replies are provided below:

"Sometimes I felt after 18 years I am being neglected as no further interest was being shown by the authorities. Maybe this is one of the causes I felt depressed occasionally. To a large extent a nurse practitioner was instrumental in taking me out of this situation. There were some small practical problems such as coping in the bathroom, travel etc. She was again helpful in contacting various persons including social services."

"The principal advantage lay in the contact with a qualified professional, away from the sometimes intimidating atmosphere of a large and busy hospital. The problems peculiar to the disease can be discussed freely and without undue tension. In my own case the obviously sincere commitment to the work was very helpful. Had circumstances demanded it I should have had no hesitation in asking the nurse practitioner for extra help and/ or advice."

"Because the nurse practitioner specializes in PD and dystonia I found it very easy to discuss my complaints and problems with her. Although I have a very caring and considerate GP her knowledge of these complaints is limited, so having the nurse practitioner to talk to I found very reassuring." 


\section{DISCUSSION}

The aims of the study were to determine whether contact with a nurse practitioner over a 6 month period would: (1) facilitate the dissemination of advice and information to the patients, and the referral of patients to other health-care agencies; (2) lead to quantifiable changes in measures of psychological well-being and adjustment; and (3) be found of value by the patients.

From the data given in Table III it is clear that the nurse practitioner was an extremely effective agent in the provision of information and in facilitating referral. A large number of the patients were judged to be eligible for either income support or mobility allowance, and were given the necessary information to pursue their application. The nurse practitioner can, therefore, play an important role in increasing the take-up rates of these benefits. A substantial number of patients were also referred on to other health-care professionals including occupational, speech and physiotherapists, dieticians, continence advisors and chiropodists. In five cases, problems were uncovered (e.g. with medication) which warranted immediate referral to the neurologist managing the patient.

Given the large practical impact of the nurse practitioner, the next question was whether this had a measurable effect on the level of adjustment and psychological well-being of the patients at the end of the trial period. The main results of the questionnaire assessment were two-fold. First, the patients with PD allocated to the "intervention" group, but not those in the control group, showed overall change suggestive of improvement on a majority of the psychosocial measures. In no instance, however, were the changes statistically significant. Second, the reverse pattern was found for the patients with dystonia, with the "control" group showing change suggestive of improvement rather than those allocated to the "intervention" group. A number of issues are relevant to the interpretation of the results of the questionnaire assessment. These relate to the nature of the samples and the duration of the intervention and follow-up. Analysis of these issues may be of value in planning future evaluation studies.

A sampling bias relating to botulinum toxin treatment is the most likely explanation for the unexpected pattern of results in the dystonia patients. In this group, $66.7 \%$ of patients allocated to the "control" group compared with $33.3 \%$ of patients in the "intervention" group were receiving botulinum toxin treatment. Botulinum toxin is currently the most effective treatment for dystonia (Stell et al., 1988) and symptomatic improvement is associated with significant im- provement of psychosocial functioning (Jahanshahi and Marsden, 1992).

Another factor that also relates to "sampling" procedures is the patient's duration of illness. Almost all patients had chronic illness. It is in the acute phase of illness, however, that the first adjustive demands are made on the patient and his family. It is possible that intervention at this stage, before any problems in psychosocial functioning have developed, might be of greater value in promoting better longterm adjustment.

A third factor related to sampling is that the subjects were randomly selected from among patients attending the National Hospital and were not specifically recruited because of a need for psychosocial intervention. It is possible that for samples specifically selected because of perceived or assessed need for psychosocial intervention, contact with a nurse practitioner may have produced significant change in the measures of psychosocial function.

In relation to the duration of the intervention, it is possible that a greater impact would have been made with a longer involvement from the nurse practitioner. Thus a number of patients maintained telephone contact even after the project ended. However, with the exception of such occasional contacts, it is reasonable to assume that the majority of the nurse practitioner's targets (information giving, assessment and referral) were achieved within the 6 month trial period.

A more realistic concern is that the 6 month trial period was insufficient for the benefits to work through into long-term adjustment and increased well-being. The practical interventions of the nurse practitioner took time to arrange. There is likely to be another time lag before the beneficial effects of the implementation of these practical interventions on psychosocial function become evident. Furthermore, the impact in the "intervention" group may be in preventing deterioration rather than in promoting actual improvement. Longer term follow-up may reveal differential effects between the "control" and "intervention" groups, in terms of a halting or slowing of the rate of deterioration.

In marked contrast to the negative findings from the main psychosocial outcome measures, it was evident from the independent assessment that the availability of contact with a nurse practitioner was well received and appreciated by the vast majority of patients within the intervention group. This positive response to nurse practitioner contact is in agreement with previous studies in the UK (Drury et al., 1988; Hill, 1986, 1992) and in the USA (Lewis and Resnick, 1967; Bystran et al., 1974; Spitzer et al., 1974) which 
examined the value of the nurse practitioner in other settings such as primary practice (Drury et al., 1988) or in the management of illnesses such as rheumatoid arthritis (Hill, 1986, 1992).

In the present study, the patients appeared to particularly appreciate the "Opportunity to talk to someone about the illness and the problems caused by it" and "Knowing that the nurse practitioner could be contacted if problems arose". Such comments presumably reflect on the patient's perceptions of the services normally available to them. All were under the care of a specialist neurologist, and all would have access to their normal general practitioner service. However, few patients would feel able to pick up the telephone and call their neurologist for help or advice. Even GPs are rarely available except through appointment, and many lack training in the specialist management of degenerative neurological disorders. The attraction of the nurse practitioner to patients, therefore, may be in his or her ready accessibility, specialist knowledge of their condition, and network of contacts with other health professionals. While knowledge of such accessibility might be a comfort to patients on a day-to-day basis, its real value would be felt when major problems occur. The nurse practitioner is ideally placed for crisis management, particularly if the patients feel that they can call him or her at any time.

\section{CONCLUSIONS}

The findings present a mixed picture of the efficacy of the nurse practitioner as a model for the management of chronic neurological disorders. The service was highly valued by the patients, and led to a high rate of new referral to other health-care agencies and take-up of state-provided benefits. However, there was no evidence that these inputs had any significant impact on adjustment and psychological well-being on the measures used.

Overall, the results are sufficiently positive, within the limitations of the study, to suggest that a longer term evaluation of the service is warranted. Such an evaluation should focus strongly on the cost-benefit of the nurse practitioner model. It is clear, even from the present preliminary results, that the nurse practitioner may actually lead to an increase in the demands made on the health service and social service budgets, at least initially. However, the nurse practitioner can have a valuable role in ensuring an adequate take-up of these provisions, and assist in the more efficient allocation of health and social security resources to those in greatest need. Such interventions may lead to long-term savings if the need for hospitali- zation or institutional care can be avoided or delayed. The other major benefit that should be evaluated is the improvement in the quality of life (QOL) of the patients and their families. It is likely that QOL measures may be more sensitive and more suitable than the measures of psychosocial function employed in the present study. Although improvement in QOL is more difficult to enter into a financial equation, it must be a clear aim of the management of chronic degenerative neurological disease.

\section{Acknowledgements}

This study was funded by a grant from the Parkinson's Disease Society (UK) and the Dystonia Society of the United Kingdom. The financial support of the Wellcome Trust, Du Pont Pharma and Roche Products Ltd is also gratefully acknowledged.

\section{REFERENCES}

Beck AT, Ward CH, Mendelson M, Mock JE and Erbaugh JK (1961) An inventory for measuring depression. Archives of General Psychiatry, 4, 561-571.

Bradburn NM (1969) The Structure of Psychological Wellbeing. Aldine, Chicago.

Brown RG, MacCarthy B, Gotham AM, Der G and Marsden CD (1988) Depression and disability in Parkinson's disease: a follow-up of 132 cases. Psychological Medicine, 18, 49-55.

Burton HJ, Stephen DPH, Kline A, Lindsay RM and Heidenheim AP (1986) The relationship of depression to survival in chronic renal failure. Psychosomatic Medicine, 48, 261-269.

Bystran SF, Knight CC, Soper MR, Collis PB, Morgan TW and Cello JP (1974) An evaluation of nurse practitioners in chronic care clinics. International Journal of Nursing Studies, 11, 185-194.

Cohen F and Lazarus R (1979) Coping with the stresses of illness. In: Health Psychology-A Handbook (Eds G Stone, F Cohen and N Adler). Jossey-Bass, San Francisco.

Drury M, Greenfield S, Stilwell B and Hull FM (1988) A nurse practitioner in general practice: patient perceptions and expectations. Journal of the Royal College of General Practitioners, 38, 503-505.

Eysenck HJ and Eysenck SBG (1975) Manual of the Eysenck Personality Questionnaire (Junior and Adult). Hodder and Stoughton, London.

Felton BJ and Revenson TA (1984) Coping with chronic illness: a study of illness controllability and the influence of coping strategies on psychological adjustment. Journal of Consulting and Clinical Psychology, 52, 343-353.

Felton BJ, Revenson TA and Hinrichsen GA (1984) Stress and coping in the explanation of psychological adjustment among chronically ill adults. Social Science and Medicine, 18, 889-898.

Folkman S and Lazarus RS (1980) An analysis of coping in middle-aged community sample. Journal of Health and Social Behavior, 21, 219-239.

Gotham AM, Brown RG and Marsden CD (1986) Depression in Parkinson's disease: a quantitative and qualitative analysis. Journal of Neurology, Neurosurgery and Psychiatry, 49, 381-389.

Behavioural Neurology . Vol 7 . 1994 
Hill J (1986) Patient evaluation of a rheumatology nursing clinic. Clinical Nursing Times, 27, 42-43.

Hill J (1992) A nurse practitioner rheumatology clinic. Nursing Standard, 7, 35-37.

Hoehn MM and Yahr MD (1967) Parkinson's disease: onset, progression and mortality. Neurology (Minneapolis), 17, 427-442.

Holmes TH and Rahe RH (1967) The Social Readjustment Rating Scale. Journal of Psychosomatic Research, 11, 213-218.

Jahanshahi M (1991) Psychosocial factors and depression in torticollis. Journal of Psychosomatic Research, 35, 493-507.

Jahanshahi $M$ and Marsden CD (1988) Depression in torticollis: A controlled study. Psychological Medicine, 18, 925-933.

Jahanshahi M and Marsden CD (1990a) Body concept, depression and disability in spasmodic torticollis. Behavioural Neurology, 3, 117-131.

Jahanshahi M and Marsden CD (1990b) A longitudinal study of depression, disability and body concept in torticollis. Behavioural Neurology, 3, 233-246,

Jahanshahi M and Marsden CD (1992) Psychological functioning before and after treatment or torticollis with botulinum toxin. Journal of Neurology, Neurosurgery and Psychiatry, 55, 229-231.

Lewis C and Resnick B (1967) Nurse clinics and progressive ambulatory care. New England Journal of Medicine, 277, 1236-1241.

MacCarthy B and Brown RG (1989) Psychosocial factors in Parkinson's disease. British Journal of Clinical Psychology, 28, 41-52.

Moos RH (1977) Coping with Physical Illness. Plenum Press, New York.

Moos RH and Solomon GF (1964) Personality correlates of the rapidity of progression in rheumatoid arthritis. Annals of Rheumatic Diseases, 23, 145-151.

Oxtoby M (1982) Parkinson's disease Patients and their Social Needs. PDS Publications.
Rosenberg MI (1965) Society and the Adolescent SelfImage. Princeton University Press, Princeton.

Royal College of Physicians (1990) Standards of care for patients with neurological disease. A consensus. Journal of the Royal College of Physicians, 24, 90-97.

Sarason BR, Levine HM, Basham R and Sarason BR (1983) Assessing social support: The Social Support Questionnaire. Journal of Personality and Social Psychology, 44, 127-130.

Shaw RE, Cohen F, Fishman-Rosen J, Murphy MC, Stertzer SH, Clark DA and Myler RK (1986) Psychosocial and medical outcomes in patients undergoing coronary angioplasty. Phychosomatic Medicine, 48, 582597.

Spielberger CD, Gorsuch RL and Lushene RE (1970) STAI Manual for the State-Trait Anxiety Inventory ('Self-Evaluation Questionnaire'). Consulting Psychologists Press, Palo Alto.

Spitzer WO, Sachett DL, Siblet JC and Roberts RS (1974) The Burlington randomized trial of the nurse practitioner. New England Journal of Medicine, 290, 251-257.

Stell R, Thompson PD and Marsden CD (1988) Botulinum toxin in spasmodic torticollis. Journal of Neurology, Neurosurgery and Psychiatry, 51, 920-923.

Turk CD (1979) Factors influencing the adaptive process with chronic illness. In: Stress and Anxiety (Eds IG Sarason and CD Spielberger). Hemisphere Publishing Corporation, Washington.

World Health Organization (1992) International Classification of Disease, tenth revision. The ICD-10 Classification of Mental and Behavioural Disorders. Clinical Description and Diagnostic Guidelines. WHO, Geneva.

(Received 19 September 1994; accepted 20 October 1994) 


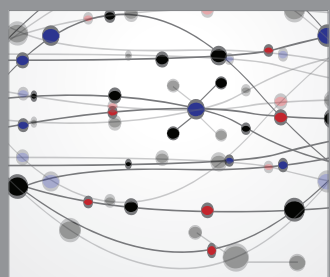

The Scientific World Journal
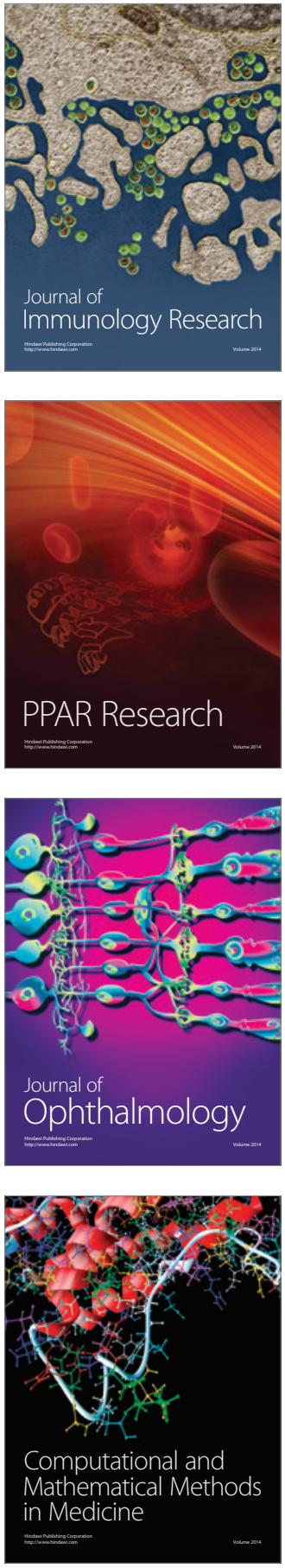

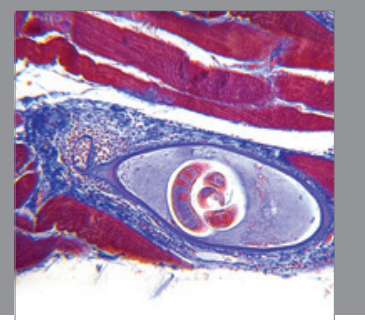

Gastroenterology

Research and Practice
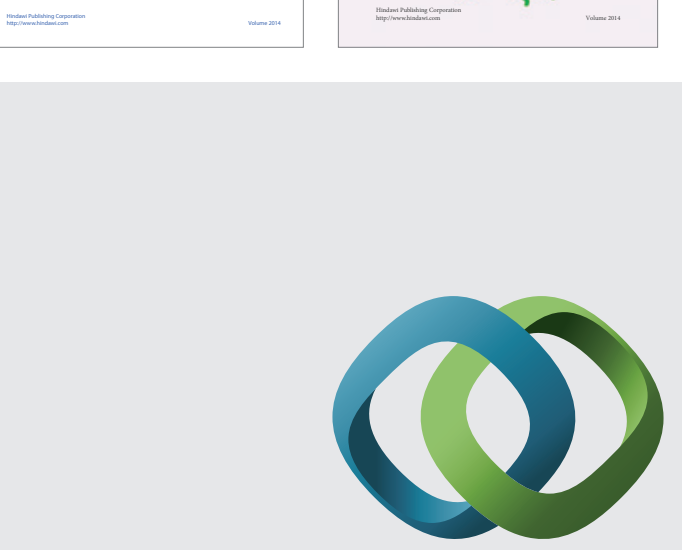

\section{Hindawi}

Submit your manuscripts at

http://www.hindawi.com
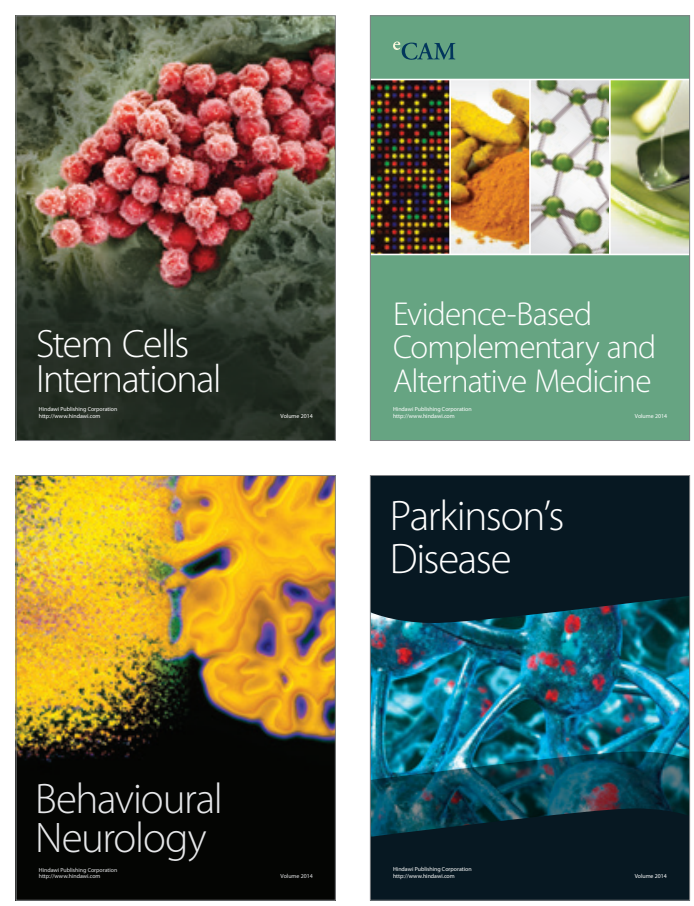

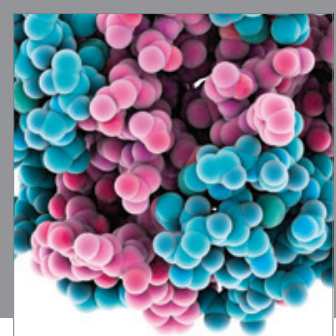

Journal of
Diabetes Research

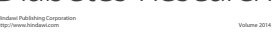

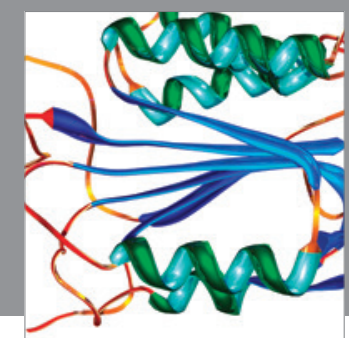

Disease Markers
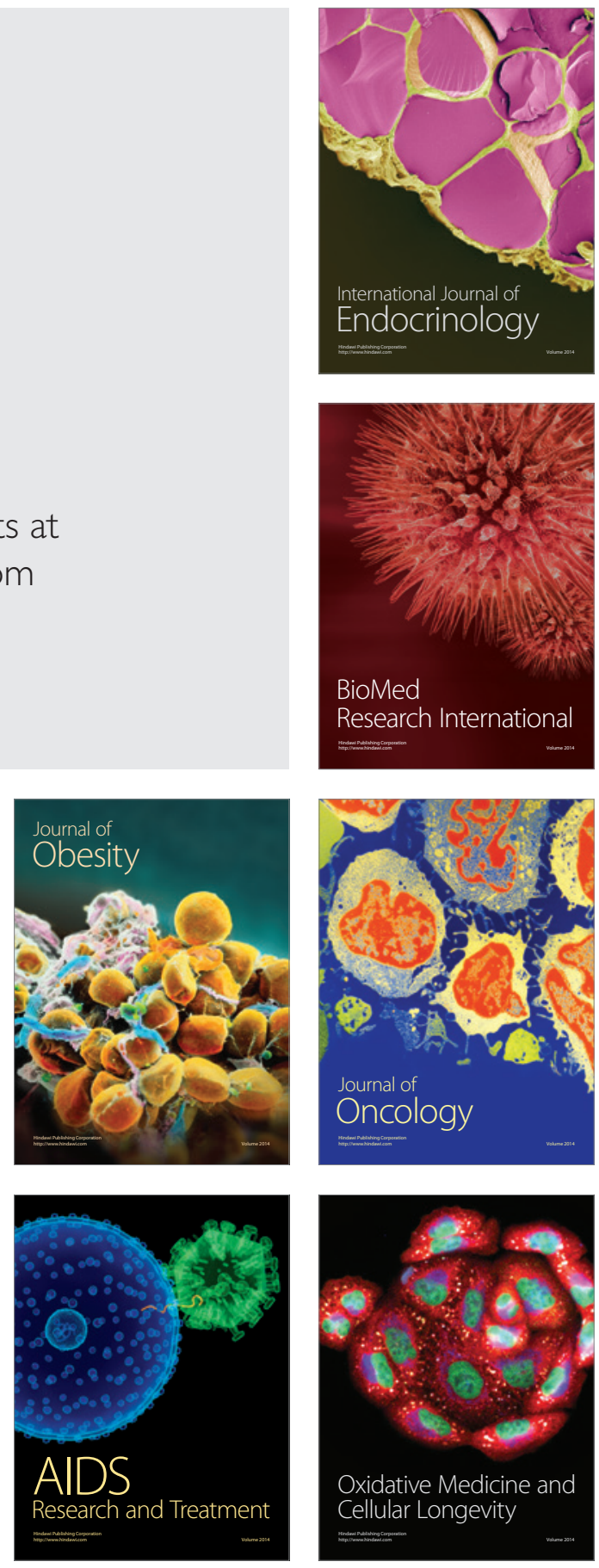